\title{
Cerebrovascular events in hemodialysis patients; a retrospective observational study
}

\author{
Ruya Ozelsancak ${ }^{*}$ D, Hasan Micozkadioglu, Dilek Torun and Nihan Tekkarismaz
}

\begin{abstract}
Background: This study reports findings in subjects who underwent brain imaging for any reason, and examined factors influencing cerebrovascular events (CVEs) in hemodialysis (HD) patients.

Methods: We reviewed the files of patients on HD between January 2015 and January 2018. A total of 432 patients who underwent HD for at least 5 months by the January 2015 and who were older than 18 years were included in the study; 264 had been examined by cerebral computed tomography or magnetic resonance imaging examination within the 3 years. Cerebrovascular pathology was detected in 139 of 264 patients.

Results: Of the 139 patients, 65 (24.62\%) had ischemic lesions, 25 (9.47\%) had hemorrhagic lesions, and 49 (18.56\%) had cerebral small vessel disease (CSVD). We compared recorded data and later clinical findings between patients with and those without CVEs. The cause of end-stage renal disease was diabetes in 58.5\% of patients with ischemic lesions, $52 \%$ in those with hemorrhagic lesions, and 55\% in those with CSVD $(P<0.05)$. Patients with cerebrovascular ischemia were older $(P=0.0001)$ and had lower serum creatinine $(\mathrm{s} C r)(P=0.0001)$ and higher serum $C$-reactive protein (CRP) $(P=0.002)$ levels than normal subjects. Hemorrhagic patients were older $(P=0.003)$ and had lower $\mathrm{s} C r(P=0.003)$ and serum predialysis potassium $(P=0.003)$ and parathyroid hormone (PTH) $(P=0.004)$ levels than normal subjects. Patients with CSVD were older $(P<0.0001)$ and had lower sCr $(P<0.0001)$, phosphorus $(P<0.007)$, and PTH $(P<0.013)$ and higher CRP $(P<0.002)$ levels than normal subjects.
\end{abstract}

Conclusions: HD patients with CVEs are older and typically have diabetes mellitus and lower sCr levels.

Keywords: Cerebrovascular event, Cerebral small vessel disease, Hemodialysis, Hemorrhage, Ischemia, Stroke

\section{Background}

Stroke is a major cause of morbidity and mortality worldwide and is a public health burden. Risk factors for stroke are similar to those for cardiac and peripheral vascular disease; non-modifiable risk factors include older age, male sex, diabetes, and family history. Diabetes mellitus (DM), hyperlipidemia, and smoking are risk factors for atherosclerosis and increase the risk of ischemic stroke; hypertension is the major modifiable risk factor for both ischemic and hemorrhagic strokes; and bleeding diathesis and blood vessel wall fragility increase susceptibility to hemorrhagic stroke $[1,2]$.

\footnotetext{
* Correspondence: rusancak@hotmail.com

Department of Nephrology, Adana Turgut Noyan Teaching and Research Center, Baskent University School of Medicine, Dadaloglu Mah, 39/6, Yuregir, 01250 Adana, PK, Turkey
}

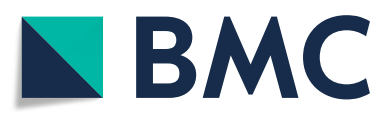

(c) The Author(s). 2019 Open Access This article is distributed under the terms of the Creative Commons Attribution 4.0 International License (http://creativecommons.org/licenses/by/4.0/), which permits unrestricted use, distribution, and reproduction in any medium, provided you give appropriate credit to the original author(s) and the source, provide a link to the Creative Commons license, and indicate if changes were made. The Creative Commons Public Domain Dedication waiver (http://creativecommons.org/publicdomain/zero/1.0/) applies to the data made available in this article, unless otherwise stated. characterized by perforation of cerebral arterioles, capillaries, and venules and imaging changes in white matter and subcortical grey matter such as small subcortical infarction, lacunes, white matter hyperintensities, prominent perivascular spaces, cerebral microbleeding, and atrophy. CSVD leads to dementia and stroke in up to 45 and $20 \%$ of cases, respectively [3].

Patients with end-stage renal disease (ESRD) have advanced atherosclerosis of the cerebral vasculature compared with the general population and require dialysis therapy, which is associated with increased risk of ischemic or hemorrhagic stroke due to the interaction between vascular comorbidities linked to kidney impairment and pathologies resulting from uremia such as vascular calcification and malnutrition-inflammation-atherosclerosis syndrome [4, 5]. 
ESRD is also associated with hypertension and bleeding diathesis, and routine administration of heparin during hemodialysis (HD) can increase the risk of hemorrhagic stroke.

Previous studies in the United States and Japan have reported 2- to 10-fold increased risk of stroke in dialysis patients compared with the general population, with the risk attributable to ESRD being greatest for older subjects and females in the United States [6-8]. Older age, male sex, diabetes, and hypertension were found to be risk factors for both ischemic and hemorrhagic strokes in a Japanese study [8].

Previous studies have shown that HD patients are more susceptible to stroke; however, these investigations have focused on overall risk and have relied on International Classification of Diseases (ICD) codes, while some patients may exhibit cerebrovascular changes without progressing to stroke. The aim of the present study was to examine patients who had undergone brain imaging for any reason (imbalance, dizziness, numbness, or paralysis) and identify factors affecting cerebrovascular events (CVEs) in HD patients.

\section{Methods}

\section{Patients}

This retrospective observational study was approved by the Clinical Research Ethics Committee of the Faculty of Medicine, Baskent University.

The files of patients who were on HD between January 2015 and January 2018 were reviewed. We included 432 patients who had undergone HD for at least 5 months by the January 2015 and who were older than 18 years. Duration of dialysis was calculated in months from start of dialysis to january 2015. Patient age, sex, dialysis duration, and comorbidities such as hypertension, DM, coronary artery disease (CAD), and renal failure were recorded. Patients who had a history of cancer or who had experienced stroke before dialysis therapy were excluded. We also recorded laboratory results (mean values) of the previous 5 months at the start of the study.

Patients who were previously diagnosed with type 1 or 2 diabetes were considered to have DM. If they had blood pressure higher than $140 / 90 \mathrm{mmHg}$ on two separate occasions or were taking anti-hypertensive medication were considered hypertensive. A history of angina pectoris, angioplasty, myocardial infarction, or congestive heart failure was defined as CAD. We also recorded laboratory parameters such as urea, creatinine $(\mathrm{Cr})$, potassium, sodium, phosphorus, serum albumin, $\mathrm{Kt} / \mathrm{V}$ (where $\mathrm{K}$ is dialyzer clearance of urea; $\mathrm{t}$ is dialysis time; and $\mathrm{V}$ is volume of distribution of urea), Creactive protein (CRP), uric acid, hemoglobin, triglyceride, total cholesterol, low-density lipoprotein cholesterol, highdensity lipoprotein cholesterol levels in blood samples drawn before the second HD session of the week.
Data for patients who underwent brain imaging [magnetic resonance imaging (MRI) or computed tomography $(\mathrm{CT})]$ for any reason (imbalance, dizziness, numbness, or paralysis) were evaluated.

\section{Statistical analysis}

Statistical analyses were performed using IBM SPSS Statistics for Windows v.17.0 (SPSS Inc., Chicago, IL, USA). Continuous variables with normal distribution are presented as the mean (standard deviation), and nonnormally distributed variables are presented as the median (range). Comparisons between two groups were carried out with the Student's $t$-test and Mann-Whitney $\mathrm{U}$ test for normally and non-normally distributed data, respectively. Categorical variables were compared between groups with the chi-square test or Fisher's exact test. $P<$ 0.05 was considered statistically significant. Then, the significant variables from the univariate model were placed in a logistic regression analysis to further analyze possible risk factors (entry: $P \leq 0.05$; removal: $P>0.1$ ).

\section{Results}

Over the 3 years of observation, 264 patients had cerebral CT or MRI. Causes and types of radiological imaging studies have shown in Table 1 . We compared the initially recorded data and subsequent clinical findings of the patients who had cerebrovascular pathology (in 139 patients, 52.6\%) and who had not. Of these, 65 (24.62\%) had ischemic lesions, 25 (9.47\%) had hemorrhagic lesions, and 49 (18.56\%) had CSVD Fig. 1. The mean ages of patients in different subgroups were as follows: normal imaging findings, $51 \pm 15$.8 years; ischemia, $61.6 \pm 13.8$ years; hemorrhage, $61 \pm 14$ years; and CSVD, $67 \pm 10$ years, with no statistically significant difference between them (Table 2). The initially recorded data and subsequent clinical findings of patients with and without CVE are compared in Table 3.

There were no differences among patients in terms of sex and time on dialysis. The cause of ESRD was diabetes in $32.8 \%$ of patients with normal imaging, $58.5 \%$ of patients with ischemic lesions, $52 \%$ of patients with hemorrhagic lesions, and $55 \%$ of patients with smallvessel ischemia $(P<0.05$; Table 2$)$. The frequency of CAD was higher in patients with CVE than in other subjects $(P=0.0001$; Table 2$)$.

We compared patients with cerebrovascular ischemia and those with normal cerebrovascular imaging findings and found that the former group was older $[61.6 \pm 13.8$ vs. $51 \pm 15.8$ years, $\mathrm{P}=0.0001]$ and had lower serum (s) Cr $[8.06 \pm 2.65$ vs. $9.09 \pm 2.42 \mathrm{mg} / \mathrm{dl}, \mathrm{P}=0.0001]$ and higher serum CRP [9 (2-68) vs. $4.8(1-103) \mathrm{mg} / \mathrm{l}, P=$ 0.002] levels than the latter.

A comparison of patients with cerebrovascular hemorrhage and normal cerebrovascular imaging findings 
Table 1 Causes and types of radiological imaging studies

\begin{tabular}{lllll}
\hline & $\begin{array}{l}\text { Ischemia } \\
\mathrm{n}(\%)\end{array}$ & $\begin{array}{l}\text { Hemorrhage } \\
\mathrm{n}(\%)\end{array}$ & Small vessel disease $\mathrm{n}(\%)$ & Normal imaging $\mathrm{n}(\%)$ \\
\hline Change of consciousness & $16(25)$ & $8(32)$ & $16(33)$ & $19(15)$ \\
Imbalance, ataxia, paralysis, numbness & $16(25)$ & $11(44)$ & $10(20)$ & $31(25)$ \\
Headache & $9(14)$ & $4(16)$ & $9(18,4)$ & $38(30)$ \\
Dizziness & $10(15)$ & - & $5(10,2)$ & $17(14)$ \\
Other: dysarthria, tinnitus, convulsions & $14(21)$ & $2(8)$ & $9(18,4)$ & $20(16)$ \\
Type of imaging & & & $25(51)$ & $88(70)$ \\
CT & $25(38)$ & $23(92)$ & $17(35)$ & $7(6)$ \\
CT + MRI & $26(40)$ & - & $7(14)$ & $30(24)$ \\
MRI & $14(22)$ & $2(8)$ &
\end{tabular}

Abbreviations: CT Computed tomography; MRI Magnetic resonance imaging

revealed that hemorrhagic patients were older [61 \pm 14 vs. $51 \pm 15.8$ years, $P=0.003]$ and had lower sCr $[7.36 \pm 2.52$ vs. $9.09 \pm 2.42 \mathrm{mg} / \mathrm{dl}, \mathrm{P}=0.003]$, predialysis serum potassium [ $4.62 \pm 0.68$ vs. $5.08 \pm 0.61 \mathrm{mEq} / \mathrm{l}, \mathrm{P}=0.003]$, and serum PTH [174 (10-1212) vs. $427(1-3145) \mathrm{pq} / \mathrm{ml}, P=$ 0.004] levels than normal subjects.

Finally, we compared patients with CSVD and those with normal cerebrovascular imaging findings. CSVD patients were older [ $67 \pm 10$ vs. $51 \pm 15.8$ years, $P=0.0001$ ] and had lower sCr $[8.51 \pm 7.06$ vs. $9.09 \pm 2.42 \mathrm{mg} / \mathrm{dL}, \mathrm{P}=$ $0.0001]$, serum phosphorus [4.3 \pm 1.57 vs. $5.00 \pm 1.36$ $\mathrm{mEq} / \mathrm{l}, P=0.007]$, and serum PTH [296 (4-1287) vs. 427 $(1-3145) \mathrm{pq} / \mathrm{ml}, P=0.013]$ levels and a higher serum CRP
[8 (2-208) vs. $4.8(1-103) \mathrm{mg} / \mathrm{l}, P=0.002]$ level than normal subjects. There were no differences in serum lipid levels and Kt/V between the two groups.

The variables which are significant in univariate analysis were evaluated by multivariate analysis. But the result of multivariate analysis were not statistically significant.

\section{Discussion}

The incidence of stroke is $2-10$ times higher in ESRD patients on dialysis than in the general population [6-8]. The initiation of dialysis is itself associated with a heightened risk of stroke. Risk factors for stroke in the

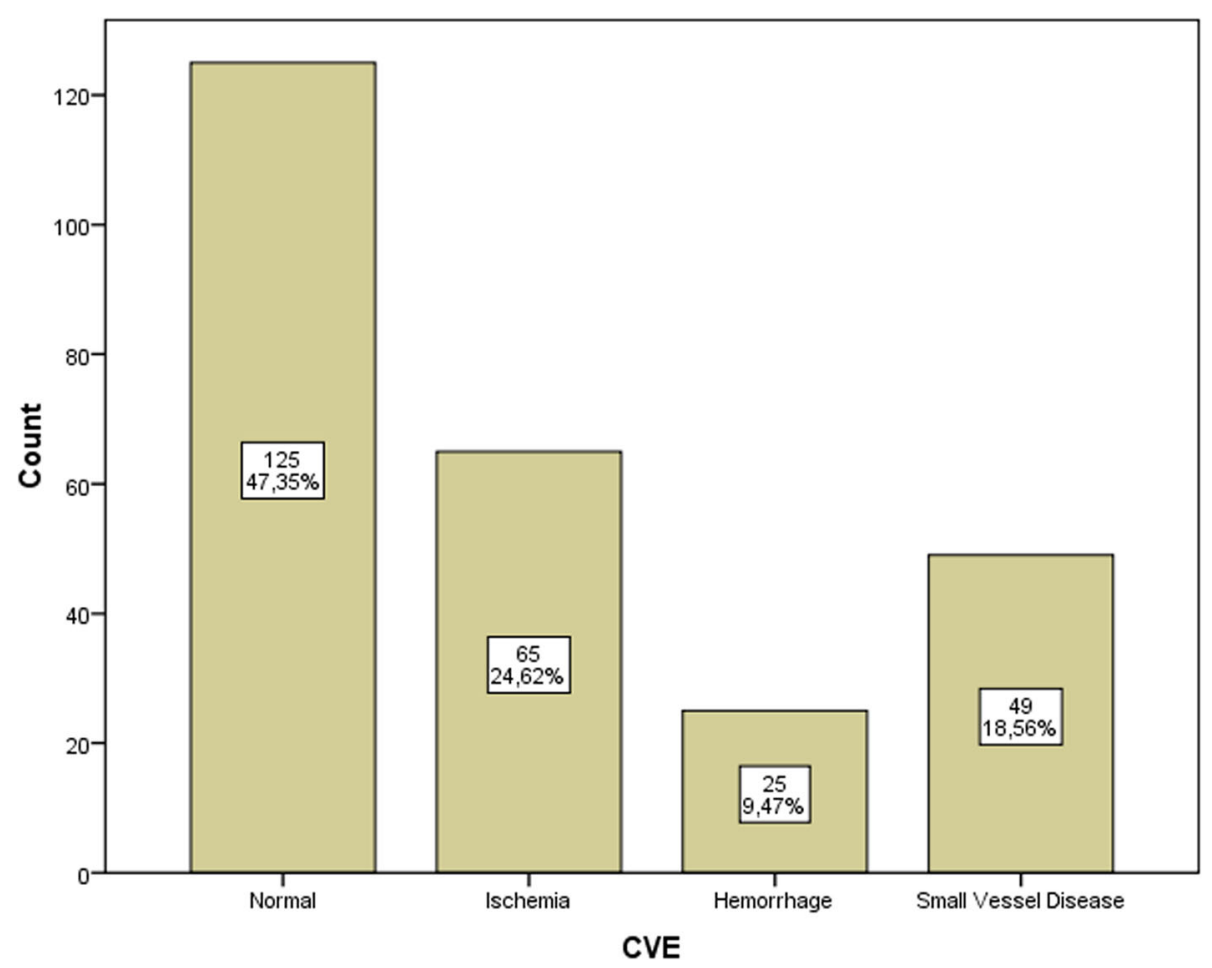

Fig. 1 Results of cerebrovascular imaging 
Table 2 Baseline demographic and clinical characteristics of patients

\begin{tabular}{|c|c|c|c|c|}
\hline & $\begin{array}{l}\text { Normal imaging } \\
(n=125,47.3 \%)\end{array}$ & $\begin{array}{l}\text { Ischemia } \\
(n=65,24.62 \%)\end{array}$ & $\begin{array}{l}\text { Hemorrhage } \\
(n=25,9.47 \%)\end{array}$ & $\begin{array}{l}\text { CSVD } \\
(n=49,18.56 \%)\end{array}$ \\
\hline Age (years) & $51 \pm 15.8$ & $61.6 \pm 13.8$ & $61 \pm 14$ & $67 \pm 10$ \\
\hline $\operatorname{Sex}(F, \%)$ & 57.6 & 63.1 & 52 & 44.9 \\
\hline Time on dialysis (months) & $43(5-200)$ & $56(6-240)$ & $48(5-216)$ & $34(6-305)$ \\
\hline \multicolumn{5}{|l|}{ ESRD etiology } \\
\hline $\mathrm{DM}, \mathrm{n}(\%)$ & $41(32,8)$ & $38(58.5)^{*}$ & $13(52)^{*}$ & $27(55)^{*}$ \\
\hline HT, n (\%) & $5(4)$ & $4(6,2)$ & $5(20)^{*}$ & $5(10)$ \\
\hline GN, n (\%) & $11(8.8)$ & $2(3.1)$ & $0(0)$ & $1(2)$ \\
\hline PKD, n (\%) & $5(4)$ & $2(3.1)$ & $0(0)$ & $3(6.1)$ \\
\hline VUR, n (\%) & $1(0.8)$ & $0(0)$ & $1(4)$ & $0(0)$ \\
\hline Other, n (\%) & $61(48.8)$ & $18(27.7)$ & $6(24)$ & $13(26.5)$ \\
\hline Unknown, n (\%) & $1(0.8)$ & $1(1.5)$ & $0(0)$ & $0(0)$ \\
\hline CAD, n (\%) & $36(28)$ & $39(60)^{*}$ & $12(48)^{*}$ & $30(61)^{*}$ \\
\hline
\end{tabular}

Abbreviations: CAD coronary artery disease; CSVD cerebral small vessel disease; DM diabetes mellitus; ESRD end-stage renal disease; GN glomerulonephritis; $H T$ hypertension; $P K D$ polycystic kidney disease; VUR vesicoureteral reflux

${ }^{*} P \leq 0.005$

general population including older age, hypertension, diabetes, obesity, and cigarette smoking also increase the risk of developing chronic kidney disease.

Despite the high prevalence of CVE in the dialysis population, the different subtypes have not been well studied in patients who have had cerebral imaging. We found here that patients with CVE were older and had lower $\mathrm{sCr}$ levels than normal subjects. While DM was the primary cause of renal failure, CAD was more frequently observed in CVE patients than in normal subjects. The risk factors for stroke identified in the present study (older age, DM, and CAD) are consistent with previous reports [8-11].
The $\mathrm{sCr}$ levels were lower in all subgroups in our study. The $\mathrm{sCr}$ originates from creatinine, which is derived from skeletal muscle and is influenced by both muscle mass and glomerular filtration rate; it can serve as a biomarker for various pathological states including ESRD, especially as an indicator of muscle mass. Low muscle mass resulting from protein-energy wasting is associated with poor outcome in HD patients; on the other hand, elevated $\mathrm{sCr}$ is linked to longer survival $[12,13]$. In the ARNOS study of 1205 patients who were followed up for 1 year, sCr level was a strong predictor of mortality, with a lower survival rate among patients with a predialysis $\mathrm{sCr}$ concentration $<8.11 \mathrm{mg} / \mathrm{dl}$ [14]. Reduced

Table 3 Laboratory values of patients

\begin{tabular}{|c|c|c|c|c|}
\hline & $\begin{array}{l}\text { Normal imaging } \\
(n=125,47.35 \%)\end{array}$ & $\begin{array}{l}\text { Ischemia } \\
(n=65,24.6 \%)\end{array}$ & $\begin{array}{l}\text { Hemorrhage } \\
(n=25,9.47 \%)\end{array}$ & $\begin{array}{l}\text { Small vessel disease } \\
(n=49,18.56 \%)\end{array}$ \\
\hline Creatinine (mg/dL) & $9.09 \pm 2.4$ & $8.06 \pm 2.6^{*}$ & $7.3 \pm 2.5^{*}$ & $8.51 \pm 7.06^{*}$ \\
\hline Potassium (mEq/l) & $5.08 \pm 0.61$ & $5.11 \pm 0.68$ & $4.62 \pm 0.68^{*}$ & $5.10 \pm 0.87$ \\
\hline Phosphorus (mg/dL) & $5 \pm 1.36$ & $4.87 \pm 1.28$ & $4.72 \pm 1.54$ & $4.30 \pm 1.57^{*}$ \\
\hline Triglyceride (mg/dl) & $193.8 \pm 131.6$ & $183.3 \pm 120.5$ & $200 \pm 145$ & $182 \pm 86.5$ \\
\hline Total cholesterol (mg/dL) & $167.4 \pm 44.6$ & $171.9 \pm 50.1$ & $177.4 \pm 50.7$ & $178.9 \pm 44.6$ \\
\hline LDL cholesterol (mg/dL) & $88.1 \pm 37.5$ & $97.2 \pm 41.2$ & $94.3 \pm 33.7$ & $101.7 \pm 35.4$ \\
\hline HDL cholesterol (mg/dL) & $40.2 \pm 13.3$ & $39.6 \pm 11.6$ & $43.5 \pm 11.7$ & $45.5 \pm 29.7$ \\
\hline PTH (pq/ml; median, min-max) & $427(1-3145)$ & $353(34-1900)$ & $174(10-1212)^{*}$ & $296(4-1287)^{*}$ \\
\hline CRP (mg/L) & $4.8(1-103)$ & $9(2-68)^{*}$ & $6(2-56)$ & $8(2-208)^{*}$ \\
\hline Uric acid (mg/dL) & $6.99 \pm 5.53$ & $6.52 \pm 1.25$ & $6.25 \pm 1.09$ & $6.61 \pm 1.24$ \\
\hline Hemoglobin (g/dL) & $11.7 \pm 1.7$ & $11.2 \pm 1.4$ & $10.8 \pm 1.3$ & $10.8 \pm 1.2$ \\
\hline $\mathrm{Kt} / \mathrm{N}$ & $1.46 \pm 10.29$ & $1.37 \pm 0.24$ & $1.47 \pm 0.22$ & $1.45 \pm 0.26$ \\
\hline
\end{tabular}

Abbreviations: CRP C-reactive protein; CSVD cerebral small vessel disease; $H D L$ high-density lipoprotein; $K t / V$ [dialyzer clearance of urea (K) $\times$ dialysis time (t)]/ volume of distribution of urea (V); LDL low-density lipoprotein; PTH parathyroid hormone $* P \leq 0.005$ 
$\mathrm{sCr}$ level reflects a loss of muscle mass or low protein intake, which can lead to adverse outcomes in HD patients.

$\mathrm{Cr}$ is a small molecule that is cleared by dialysis; predialysis $\mathrm{sCr}$ level may thus be influenced by the dialysis dose in the preceding session, i.e., a higher dose may lower predialysis $\mathrm{Cr}$. We were unable to confirm muscle mass and establish the precise mechanism by which decreased $\mathrm{sCr}$ causes CVEs; there have been no studies reporting either a negative or positive association between these two parameters. However, one study investigating the relationship between modified $\mathrm{Cr}$ index (which was calculated based on age, sex, predialysis $\mathrm{sCr}$ concentration, and $\mathrm{Kt} / \mathrm{V}$ for urea) for cardiovascular events and all-cause mortality in patients undergoing HD showed that mortality and risk of heart disease were significantly higher in the lower quartiles, while modified $\mathrm{Cr}$ index was unrelated to stroke [15]. Thus, the role of $\mathrm{sCr}$ concentration in CVE and stroke risk remains unclear.

Many ESRD patients have chronic inflammation. In our study, CRP level was higher in ischemic and CSVD patients. Inflammation contributes to the development of atherosclerosis. In the Rotterdam Scan Study, subjects with elevated CRP levels had a higher frequency of lacunar infarcts than the general population [16]. The LIMIT study showed that compared with the bottom quartile, subjects with CRP in the top quartile were at increased risk of recurrent ischemic stroke, implying that CRP predicts the occurrence of major vascular events [17]. However, these studies were carried out in patients with normal renal function. It has been reported that HD patients show a higher rate of silent cerebral infarctions, which is reflected by elevated CRP [18]. On the other hand, another report found no association between CRP level and risk of cerebrovascular events in HD patients [19].

We observed that predialysis serum potassium concentration was lower in hemorrhagic stroke patients. A study in rats showed that a high potassium diet allowed cerebral arteries to withstand high blood pressure and reduced damage to the artery wall, thereby preventing brain hemorrhage and infarct and lowering mortality rate. Hypertension does not inevitably lead to arterial hypertrophy because it can be alleviated by a high-potassium diet [20,21]. In a rat model of ischemic stroke, dietary potassium supplementation reduced infarct size in cerebral ischemia by reversing cerebral artery hypertrophy and providing neuroprotection independent of blood pressure, possibly through changes in vascular structure [22]. Given that the primary excretion route of potassium is through the kidney, ESRD patients should be given a potassium-restricted diet as it is difficult to maintain normokalemia during dialysis.

PTH was low in patients with CSVD or in those who experienced hemorrhagic events. Higher PTH levels have been previously observed in stroke patients [23]. In the Atherosclerosis Risk in Communities brain MRI study, a cross-sectional analysis revealed that elevated PTH level was associated with higher white matter hyperintensity score (a sign of CSVD) and more frequent infarcts. White matter hyperintensities of presumed vascular origin are a common finding in brain MRI or CT scans in older subjects and stroke patients, and are associated with a three times higher risk of stroke. However, these authors did not find an association between elevated PTH level and progression of cerebrovascular changes in brain MRI over a 10-year interval [24]. A longitudinal study of HD patients in the Japan Renal Data Registry found that hemorrhagic stroke was associated with PTH concentration $>500 \mathrm{pg} / \mathrm{ml}$, whereas the incidence of ischemic stroke was unrelated to PTH level [25]. The PTH receptor is expressed on endothelial cells, vascular smooth muscle cells, and cardiomyocytes. PTH induces the expression of proinflammatory and atherosclerotic mediators including interleukin- 6 and receptor of advanced glycation end products in endothelial cells [26]. The association between PTH and atherogenesis can be explained by vascular calcification and remodeling resulting from the direct interaction of PTH with its receptor on the vessel wall, indirect inflammation, and vascular dysfunction [27]. Most of our patients were taking calcium containing phosphorus binders, which could be the reason for low PTH concentration in those who experienced hemorrhagic events or with CSVD, although the levels were still higher than normal. The use of calcium-containing phosphorus binders can lead to vascular calcification; the resulting impairment in vessel elasticity may cause bleeding in cerebral vessels upon sudden blood pressure changes [28].

\section{Conclusions}

The major findings of this study were the decreased $\mathrm{Cr}$ and potassium levels in CVE patients. Although serum $\mathrm{PTH}$, potassium, and phosphorus were lower and CRP was higher in some subjects, we were unable to determine the relationship between these findings and CVEs due to the observational design of the study. On the other hand, we examined all of the cerebral imaging results of patients rather than simply searching stroke ICD codes in the database; we think this was an important point in terms of detecting cerebral changes that do not lead to stroke.

There were several limitations to our study including its observational nature and small sample size, which prevented the establishment of a causal relationship between our observations. We also lacked patient information such as smoking status, body mass index, and physical activity. Additionally, given that we excluded patients with prior events, we were unable to identify 
recurrent events during the observational period. On the other hand, we did not exclude a small group of patients who had undergone parathyroidectomy as well as HD for ultrafiltration due to heart failure.

\section{Abbreviations}

CAD: Coronary artery disease; CRP: C-reactive protein; CSVD: Cerebral small vessel disease; CT: Computed tomography; CVEs: Cerebrovascular events; DM: Diabetes mellitus; ESRD: End-stage renal disease; HD: Hemodialysis; MRI: Magnetic resonance imaging; PTH: Parathyroid hormone; sCr: Serum creatinine

\section{Acknowledgments}

Statistical analyses were performed by Cagla Sarıturk.

\section{Authors' contributions}

$\mathrm{RO}, \mathrm{HM}, \mathrm{DT}$ and NT participated in designing the research, writing the paper, performing the research, collecting the data, and analyzing the data. All authors have read and approve of the final version of the manuscript.

\section{Funding}

The authors did not receive any funding for this work.

\section{Availability of data and materials}

The datasets analyzed during the current study are available from the corresponding author on reasonable request.

\section{Ethics approval and consent to participate}

This study was conducted in compliance with the ethical standards of the Declaration of Helsinki and was approved by the Clinical Research Ethics Committee of the Faculty of Medicine, Baskent University. Written informed consent was waived because of the retrospective and noninvasive nature of this study.

\section{Consent for publication}

All the authors gave their consent for the publication of this article. The results presented in this paper have not been published previously in whole or part, except in abstract form. That study has been presented at 55th ERAEDTA congress which hold between 24 and 27 May 2018 in Copenhagen.

\section{Competing interests}

The authors declare that they have no competing interests.

\section{Received: 26 July 2019 Accepted: 18 November 2019}

\section{Published online: 12 December 2019}

\section{References}

1. O'Donnell MJ, Xavier D, Liu L, et al. Risk factors for ischaemic and intracerebral haemorrhagic stroke in 22 countries (the INTERSTROKE study): a case-control study. Lancet. 2010;376(9735):112-23. https://doi.org/10.1016/ S0140-6736(10)60834-3.

2. Power A. Stroke in dialysis and chronic kidney disease. Blood Purif. 2013; 36(3-4):179-83. https://doi.org/10.1159/000356086.

3. Shi Y, Wardlaw JM. Update on cerebral small vessel disease: a dynamic whole-brain disease. Stroke Vasc Neurol. 2016;1(3):83-92. https://doi.org/10. 1136/svn-2016-000035.

4. Kuo CC, Lee CT, Ho SC, Kuo HW, Wu TN, Yang CY. Haemodialysis and the risk of stroke: a population-based cohort study in Taiwan, a country of high incidence of end-stage renal disease. Nephrology. 2012;17(3):243-8. https:// doi.org/10.1111/j.1440-1797.2011.01551.x.

5. Yao Q, Pecoits-Filho R, Lindholm B, Stenvinkel P. Traditional and nontraditional risk factors as contributors to atherosclerotic cardiovascular disease in end-stage renal disease. Scand J Urol Nephrol. 2004;38(5):405-16.

6. Seliger SL, Gillen DL, Longstreth WT Jr, Kestenbaum B, Stehman-Breen CO. Elevated risk of stroke among patients with end-stage renal disease. Kidney Int. 2003;64(2):603-9.

7. Iseki K, Kinjo K, Kimura Y, Osawa A, Fukiyama K. Evidence for high risk of cerebral hemorrhage in chronic dialysis patients. Kidney Int. 1993:44(5): 1086-90.
8. Wang HH, Hung SY, Sung JM, Hung KY, Wang JD. Risk of stroke in longterm dialysis patients compared with the general population. Am J Kidney Dis. 2014;63(4):604-11. https://doi.org/10.1053/j.ajkd.2013.10.013.

9. Fu J, Huang J, Lei M, et al. Prevalence and Impact on Stroke in Patients Receiving Maintenance Hemodialysis versus Peritoneal Dialysis: A Prospective Observational Study. PLoS One. 2015;10(10):e0140887. https:// doi.org/10.1371/journal.pone.0140887.

10. Power A, Chan K, Singh SK, Taube D, Duncan N. Appraising stroke risk in maintenance hemodialysis patients: a large single-center cohort study. Am J Kidney Dis. 2012;59(2):249-57. https://doi.org/10.1053/j.ajkd.2011.07.016.

11. Iseki K. Fukiyama K; Okawa Dialysis study (OKIDS) group. Clinical demographics and long-term prognosis after stroke in patients on chronic haemodialysis. The Okinawa Dialysis study (OKIDS) group. Nephrol Dial Transplant. 2000;15(11):1808-13.

12. Walther $C P$, Carter CW, Low CL, et al. Interdialytic creatinine change versus predialysis creatinine as indicators of nutritional status in maintenance hemodialysis. Nephrol Dial Transplant. 2012;27(2):771-6. https://doi.org/10. 1093/ndt/gfr389.

13. Kalantar-Zadeh K, Streja E, Molnar MZ, et al. Mortality prediction by surrogates of body composition: an examination of the obesity paradox in hemodialysis patients using composite ranking score analysis. Am J Epidemiol. 2012;175(8):793-803. https://doi.org/10.1093/aje/kwr384.

14. Moreau-Gaudry X, Guebre-Egziabher F, Jean G, et al. Serum creatinine improves body mass index survival prediction in hemodialysis patients: a 1year prospective cohort analysis from the ARNOS study. J Ren Nutr. 2011; 21(5):369-75. https://doi.org/10.1053/j.jrn.2010.08.005.

15. Arase $H$, Yamada S, Yotsueda R, et al. Modified creatinine index and risk for cardiovascular events and all-cause mortality in patients undergoing hemodialysis: the Q-cohort study. Atherosclerosis. 2018;275:115-23. https:// doi.org/10.1016/j.atherosclerosis.2018.06.001.

16. van Dijk EJ, Prins ND, Vermeer SE, et al. C-reactive protein and cerebral small-vessel disease: the Rotterdam scan study. Circulation. 2005;112(6): 900-5.

17. Elkind MS, Luna JM, McClure LA, et al. C-reactive protein as a prognostic marker after lacunar stroke:levels of inflammatory markers in the treatment of stroke study. Stroke. 2014:45(3):707-16. https://doi.org/10.1161/ STROKEAHA.113.004562.

18. Anan F, Shimomura T, Kaku T, et al. High-sensitivity C-reactive protein level is a significant risk factor for silent cerebral infarction in patients on hemodialysis. Metabolism. 2008;57(1):66-70.

19. Sozio SM, Coresh J, Jaar BG, et al. Inflammatory markers and risk of cerebrovascular events in patients initiating dialysis. Clin J Am Soc Nephrol. 2011;6(6):1292-300. https://doi.org/10.2215/CJN.08350910.

20. Tobian L. High-potassium diets markedly protect against stroke deaths and kidney disease in hypertensive rats, an echo from prehistoric days. J Hypertens Suppl. 1986;4(4):S67-76.

21. Tobian $L$, Lange JM, Johnson MA, et al. High-K diets reduce brain haemorrhage and infarcts, death rate and mesenteric arteriolar hypertrophy in stroke-prone spontaneously hypertensive rats. J Hypertens Suppl. 1986: 4(5):S205-7

22. Dorrance AM, Pollock DM, Romanko OP, Stepp DW. A high-potassium diet reduces infarct size and improves vascular structure in hypertensive rats. Am J Physiol Regul Integr Comp Physiol. 2007;292(1):R415-22.

23. Çelik G, Doğan A, Dener \$̧, Öztürk \$̧, Kulaksızoğlu S, Ekmekçi H. Parathyroid Hormone Levels in the Prediction of Ischemic Stroke Risk. Dis Markers. 2017. 2017:4343171. https://doi.org/10.1155/2017/4343171.

24. Korada SK, Zhao D, Gottesman RF, et al. Parathyroid hormone and subclinical cerebrovascular disease: the atherosclerosis risk in communities brain magnetic resonance imaging study. J Stroke Cerebrovasc Dis. 2016; 25(4):883-93. https://doi.org/10.1016/j.jstrokecerebrovasdis.2015.12.029.

25. Tagawa M, Hamano T, Nishi H, et al. Mineral metabolism markers are associated with myocardial infarction and hemorrhagic stroke but not ischemic stroke in hemodialysis patients: a longitudinal study. PLoS One. 2014;9(12):e114678. https://doi.org/10.1371/journal.pone.0114678 eCollection 2014.

26. Rashid G, Bernheim J, Green J, Benchetrit S. Parathyroid hormone stimulates endothelial expression of atherosclerotic parameters through protein kinase pathways. Am J Physiol Renal Physiol. 2007;292(4):F1215-8.

27. Hagström E, Hellman P, Larsson TE, et al. Plasma parathyroid hormone and the risk of cardiovascular mortality in the community. Circulation. 2009; 119(21):2765-71. https://doi.org/10.1161/CIRCULATIONAHA.108.808733. 
28. Block GA, Spiegel DM, Ehrlich J, et al. Effects of sevelamer and calcium on coronary artery calcification in patients new to hemodialysis. Kidney Int. 2005;68(4):1815-24.

\section{Publisher's Note}

Springer Nature remains neutral with regard to jurisdictional claims in published maps and institutional affiliations.

Ready to submit your research? Choose BMC and benefit from:

- fast, convenient online submission

- thorough peer review by experienced researchers in your field

- rapid publication on acceptance

- support for research data, including large and complex data types

- gold Open Access which fosters wider collaboration and increased citations

- maximum visibility for your research: over $100 \mathrm{M}$ website views per year

At $\mathrm{BMC}$, research is always in progress. 